\title{
Prevalence and Associated Factors of Musculoskeletal Disorders Among Municipal Solid Waste Disposal Male Workers in a Selected Area of Dhaka City
}

\author{
Jasim Uddin ${ }^{1}$, A. S. M. Giasuddin ${ }^{2,3,}$, M. I. Khalil ${ }^{4}$, M. Kamrujjaman ${ }^{4}$ \\ ${ }^{1}$ Department of Physiotherapy, State College of Health Sciences, Dhanmondi, Dhaka-1209, Bangladesh. \\ ${ }^{2}$ Medical research Unit (MRU), Medical College for Women \& Hospital (MCW\&H), Medical \& Health Welfare Trust (MHWT), \\ Uttara Model Town, Dhaka-1230, Bangladesh. \\ ${ }^{3}$ Impulse Hospital, ImHS\&RCLtd, 304/E, Tejgaon Industrial Area, Dhaka-1208, Bangladesh. \\ ${ }^{4}$ Department of Physiotherapy, State College of Health Sciences, Dhanmondi, Dhaka-1209, Bangladesh.
}

How to cite this paper: Jasim Uddin, A. S. M. Giasuddin, M. I. Khalil, M. Kamrujjaman. (2022) Prevalence and Associated Factors of Musculoskeletal Disorders Among Municipal Solid Waste Disposal Male Workers in a Selected Area of Dhaka City. International Journal of Clinical and Experimental Medicine Research, 6(1), 31-39.

DOI: 10.26855/ijcemr.2022.01.006

Received: October 21, 2021

Accepted: November 18, 2021

Published: December 14, 2021

*Corresponding author: A. S. M. Giasuddin, Medical research Unit (MRU), Medical College for Women \& Hospital (MCW\&H), Medical \& Health Welfare Trust (MHWT), Uttara Model Town, Dhaka-1230, Bangladesh; Impulse Hospital, ImHS\&RCLtd, 304/E, Tejgaon Industrial Area, Dhaka-1208, Bangladesh.

Email: asmgias@hotmail.com

\begin{abstract}
Background: Wide range of activities involved in municipal solid waste (MSW) management may lead to development of musculoskeletal disorders (MSDs) in MSW disposal male workers. Not much studies were done about the prevalence and associated factors of MSDs in MSW disposal male workers in Bangladesh; Objectives: To determine the prevalence and associated factors of (MSDs) among MSW disposal male workers in a selected area of Dhaka City, Bangladesh; Methodology: A total of 102 MSW disposal male workers $(\mathrm{n}=102)$ were included in the study by convenient sampling procedure. A structured questionnaire was used to collect the information/data by face to face interview for 6 months (January to June 2021) from the selected area of Dhaka city. Data were numerically coded and captured in Excel using SPSS Software Programme-Version 22 and subjected to cross sectional analyses by Chi-squired (X) tests; Results: Socio-demographic, ergonomic, MSDs/pain, work/career, posture and treatment seeking pattern related information were obtained and recorded of the 102 respondents (age range: 18-67 years, majority age range: $18-27$ years ie.59/57.8\%, married: $75 / 73.5 \%$, unmarried: $27 / 26.5 \%$, majority: $n=68 / 66.7 \%$ had normal $B M I / 18.5-24.9$, career period: 1 -30 years and majority: $n=79 / 78.4 \%$ were illiterate). Types of work varied as collection, transfer and two or more with postures as standing $(\mathrm{N}=87,85.3 \%)$, sitting $(\mathrm{n}=2,2.0 \%)$, bending $(\mathrm{n}=101,99.0 \%)$ and all types $(\mathrm{n}=1,1.0 \%)$ indicating multiple working postures for individuals. MSDs were present in 85 (83.3\%) and absent in 17 (16.7\%) respondents. Pattern of pain varied as temporary $(n=74,88.1 \%)$, continuous $(n=3,3.6 \%)$ and on movement $(n=39,46.4 \%)$. About severity of pain, $1 \%(n=1)$ had mild, 73\% $(n=62)$ had moderate and $26 \%(n=22)$ had severe type of pain and $16.7 \%(n=17)$ had no response to pain. Location of pain $(n=85)$ were in neck $(54.1 \%, n=46)$, shoulder $(80.0 \%, n=68)$, elbow joint $(8.2 \%, n=7)$, wrist joint $(7.1 \%, n=6)$, upper back pain $(15.3 \%, n=13)$, lower back pain $(90.6 \%, n=77)$, knee joint $(23.5 \%, n=20)$ and ankle joint $(2.4 \%, n=2)$ indicating that each of them had pain in multiple locations. Of them $(n=85,83.3 \%), 50(49 \%)$ received treat-
\end{abstract}


ment from doctors $(n=47,94 \%)$, physiotherapists $(n=1,2 \%)$, others $(n=2,4 \%)$ and 35 (34.3\%) did not receive treatment. Among the 50 treated patients, condition improved in 17 (16.7\%), worsened in $1(1.0 \%)$ and unchanged in 32 (31.4\%) of them. Statistical analyses indicated that age $(\mathrm{p}=0.167)$, BMI $(\mathrm{p}=0.155)$, education level $(\mathrm{p}=0.329)$ and career period $(\mathrm{p}=0.293)$ were not significantly associated with MSDs in our respondents; Conclusions: An integrated health education consisting of ergonomics and healthy work habits needs to be incorporated in a pre-health screening programme. Also, a routine workplace health promotion model needs to be activated for these workers. Further analytical and interventional studies are warranted involving more respondents from wider areas of Bangladesh including Dhaka city to evaluate the effectiveness of information related intervention.

\section{Keywords}

MSDs, Municipality, Solid Waste, Disposal Workers, Prevalence

\section{Introduction}

Municipal solid wastes (MSWs) are produced and discarded every day and it can lead to pollution if it is not collected, treated and disposed regularly. MSWs include many different things including food and garden waste, product packaging, plastics, glass, metals, furniture, clothing, electrical appliances and medical wastes, i.e., wastes from households, commercials and medical institutions [1, 2]. Despite waste collection has been contributing greatly to human health by reducing the risk of several infectious diseases, workers are at high risk of fatal and non-fatal occupational accidents [3]. Waste collection is therefore a necessary activity all around the world and removal of MSWs is a job associated with a variety of biological, chemical, mechanical, physical and psychological hazards. In many developing countries including Bangladesh and Malaysia, MSWs are collected manually which requires repeated heavy physical endeavour such as lifting, carrying, pulling and pushing. Risks occur at every step in the MSWs management process, from the point of collection at homes, during transportation and at the sites of recycling or disposal [4]. MSW disposal workers play an important role towards the effectiveness of the waste management strategy planned by the local authority to ensure cleanliness of the country [5].

One of the occupational health hazards is work-related musculoskeletal disorders (MSDs). Symptoms of MSDs may develop from exposure to work activities that require repetitive motions, frequent use of muscles and tendons in an awkward posture and lifting heavy load. Most importantly MSDs may be due to long exposure to those aforementioned risks which many researchers called them as ergonomic risk factors [6]. The findings on the cause and effect relationship between ergonomic risk factors and the development of work-related MSDs among these workers were reported [7]. Socioeconomic status of waste disposal workers was low and their working conditions were unfavorable [8]. The risk of diseases resulting from exposure to various work hazards as well as risk of fatal and nonfatal occupational accidents for them is very high. Musculoskeletal problems are also common among waste collectors and nonfatal injuries are mainly musculoskeletal [9-11].

MSDs are an important public health problem in both developed and developing countries, with substantial negative impact on the quality of life. MSDs contribute to absenteeism, increased work restriction, transfer to other jobs, or disability with a considerable economic toll on the individual, the organization, and the society as a whole [12-14]. Moreover, MSDs are the most expensive form of work disability. Workplace activities such as heavy lifting, manual handling, prolonged sitting and standing, bending, and other repetitive tasks are known as risk factors for MSDs [15, 16]. Although MSDs represent a significant occupational issue for MSW disposal workers worldwide, there has been little study on the health and incidence of MSDs among MSW disposal workers in developing countries like India, Bangladesh and others as indicated by literature review [17].

Evidence suggests that workers engaged in manual solid waste collection are vulnerable, due to inadequate protective measures, to various occupational health hazards such as respiratory disorders, gastrointestinal diseases, skin diseases, eye infections, headache and MSDs as compared to the general population due to the nature of their work $[8,18,19]$.

The municipal waste loading occupation involves nature of work including lifting, pulling, pushing, bending 
during the collection of waste materials and loading it into garbage compactors and lifting heavy loads to a higher loading position and unloading it on landfills increases the episodes of MSDs [20, 21].

One systematic review showed that the occupational accident rate among Danish MSW workers was 5.6 times higher than that of total work-force [3, 8]. The standards and norms for handling MSW in developed countries have reduced its occupational health impacts substantially. However, in developing countries solid waste workers and waste pickers are at much higher risk of occupational injuries [22-24]. In developing countries, the collection system is labor-intensive, workers have less protection, most waste is not safely contained in readily liftable load sizes, re-cycling are conducted from mixed waste, many waste pickers are children or women of child-bearing age, disposal is open dumping, disposal equipment operators are not in closed air conditioned [23, 25, 26].

Two studies conducted in Addis Ababa and Northwest Ethiopia showed that the prevalence of occupational injuries among solid waste workers were $43.7 \%$ and $63.9 \%$ respectively [22, 27]. Refuse collection is a hazard laden job which include injuries and possible infections from sharp objects such as broken glasses, serrated edges of tin cans, knives protruding as bags are lifted or swung and hypodermic needles. Solid waste collectors are exposed to increasing risk of injuries and probable respiratory and gastrointestinal tract diseases also [28, 29].

The present study was therefore undertaken with (i) General Objective: To determine the prevalence and associated factors of MSDs among the MSW disposal male workers and (ii) Specific Objectives: To explore the socio-demographic characteristics of MSW disposal male workers with MSDs; To establish the different body parts and the associated factors involved with MSDs; To find the number of experiences and episodes of MSDs among the MSW disposal male workers; To determine types of treatments received and consequences occurred. This study might help to set up prevention strategies for policy making and problem solving by discovering the magnitude and risk factors of MSDs.

\section{Methodology}

Operational Definitions: The operational definitions for Pain according to International Association for the Study of Pain (IASP), Municipal, Municipal Solid Wastes (MSWs), MSW Workers, Domestic Waste Pickers (DWPs), Prevalence, Musculoskeletal Disorders (MSDs), Visual Analogue Scale (VAS), Body Mass Index (BMI) according to International Obesity Task Force, were made according to standard procedures and practices for biomedical sciences research including Physiotherapy. These definitions were relevant to our research objectives and research question, i.e., What was the prevalence and associated factors of MSDs among the MSW disposal male workers in a selected area of Dhaka City?

Study Design: A quantitative research model in the form of a cross-sectional study design was used to identifying a defined population at a particular point in time and comparing results among respondents of different age, gender, or ethnicity; Study Site: MSDs among MSW disposal male workers; Study Area: A selected area of Dhaka city; Study Period: Six months, i.e., January to June 2018; Study Population and Sampling Procedure: All municipal solid waste workers of Dhaka who fulfilled the inclusion and exclusion criteria were the study population of this research. The non-probability convenience sampling procedure was used due to time limitation and small population size as it was easier, cheaper and quicker method of sample selection; Inclusion Criteria: Only male patients (respondents) medically stable with age range $\geq 18$ years and willing to participate in the study; Exclusion criteria: Subjects who were medically unstable, female patients; male patients age range below <18 years and not willing to participate in the study; Sample Size: The sample size was calculated using the equation $\mathrm{n}=\mathrm{Z}^{2} \mathrm{pq} / \mathrm{d}^{2}$, where, $\mathrm{n}=$ Desired sample size; $\mathrm{z}=$ Standard normal deviate usually set at 1.96 which correspondents to $95 \%$ confidence level; $p=$ Proportion of the target population estimated to have particular characteristics (0.653); $q=1-p(1-0.653)=0.347 ; \mathrm{d}=$ Degree of accuracy desired usually set at 95\% expressed in decimal (0.05). Accordingly, the calculated sample size was $=347.6565=348$. Out of the 348 actual sample size, due to time limitation and financial constraints, sample size was limited to 102; Data Collection Tools and Methods: Data were collected by using both structured and semi structured mixed type questionnaire after obtaining consent and asking pre-determine questions to the participants and given time to understand the questions fully so that they answered accurately; Data Analysis: Data were analyzed using the software 'Statistical Package for Social Sciences (SPSS) programme Version 22.0'. Data were resolved numerically coded and captured in Microsoft Excel using SPSS version 22.0 and Microsoft Office Excel 2007 was used to decorate the table, bar graph, pie charts etc; Ethical Consideration: The research proposal was approved by the ethical committee of Physiotherapy Department strictly following the procedures laid down by SCHS Ethical Review Committee based on WHO and BMRC guidelines [30]. 


\section{Results}

The “Questionnaire” developed was used to obtain information from MSW disposal male workers (respondents) about their socio-demographic factors, Ergonomic related information, MSDs and related treatment seeking patterns. The information obtained from respondents were analyzed statistically constituting the contents of results as noted down.

\subsection{Socio-Demographic Information}

The overall age range of the respondents $(\mathrm{n}=102)$ was 18-67, the mean (age 28.47+-10.6) years. Among them, respondents $57.8 \%(n=59), 24.5 \%(n=25), 11.8 \%(n=12), 3.9 \%(n=4)$ and $2.0 \%(n=2)$ were in the age range of 18-27 years, 28-37 years, 38-47 years, 48-57 years and 58-67 years respectively. The highest number of respondents $(n=59)$ were in the first age group, i.e., 18-27 years. Regarding marital status, $73.5 \%(n=75)$ were married and $26.5 \%(n=27)$ were unmarried respectively. BMI of the respondents $(n=102)$ were in ranges of $<18.5$ (Underweight) (25.5\%, $n=26), 18.5-24.9$ (Normal) $(66.7 \%, n=68), 25-29.9$ (Overweight) $(0.0 \%, n=0)$ and 30 or above (Obese) $(7.8 \%, \mathrm{n}=8)$, respectively.

Among the respondents $(n=102), 2.9 \%(n=4), 56.9 \%(n=58)$ and $39.2 \%(n=40)$ had $1-4,5-8$ and 9-12 family members, respectively. Individual monthly income of the respondents varied from 10,000-14,000 taka (37.2\%, $\mathrm{n}=38)$ ) and $15,000-19,000$ taka $(62.7 \%, \mathrm{n}=64)$, respectively. The family monthly income varied from $16,000-25,000$ taka $(40.2 \%, n=41), 26,000-35,000$ taka $(36.3 \%, n=37), 36,000-45,000$ taka $(18.6 \%, n=19)$, $46,000-55,000$ taka $(2.0 \%, n=2)$ and $56,000-65,000$ taka $(2.9 \%, n=3)$, respectively. Education levels of the respondents $(n=102)$ were illiterate $(78.4 \%, n=80)$, able to read and write $(10.8 \%, n=11)$, below primary level $(8.8 \%$, $\mathrm{n}=9)$ and above primary level $(2.0 \%, \mathrm{n}=2)$, respectively.

\subsection{Ergonomic Related Information}

Distribution of the respondents $(\mathrm{n}=102)$ based on period of work (career) revealed that $6(5.9 \%), 29(28.4 \%), 33$ (32.4), 17 (16.7\%), 8 (7.8\%) and 4 (3.9\%) belonged to ranges of 1-5 years, 6-10 years, 11-15 years, 16-20 years, 21-25 years and 26-30 years, respectively. Distribution of the respondent based on types of work (job) showed that $46.1 \%(n=47), 46.1 \%(n=47)$ and 53.9\% ( $n=55)$ were assigned to collection, transfer and two or more jobs (work), respectively. The respondents had multiple work assignments and their working postures showed that $85.3 \%$ $(\mathrm{n}=87), 2.0 \%(\mathrm{n}=2), 99.0 \%(\mathrm{n}=101)$ and $1.0 \%(\mathrm{n}=1)$ of them maintained standing, sitting, bending and all three postures, respectively.

\subsection{MSDs related Information}

About the distribution of the respondents $(\mathrm{n}=102)$ based on presence of MSDs showed that $83.3 \%(\mathrm{n}=85)$ had and $16.7 \%(n=17)$ had no MSDs. Regarding the severity in 85 respondents having MSDs, $1 \%(n=1), 73 \%(n=62)$ and 26\% ( $n=22)$ had mild, moderate and sever type of MSDs, respectively. The distribution of respondents based on pattern of pain and duration of pain are stated in Table 1 and Table 2, respectively.

About location of MSDs in the 85 respondents, 54.1\% $(n=46)$ had neck pain, 80.0\% ( $n=68)$ had shoulder pain, 8.2\% $(n=7)$ had pain in elbow joint, 7.1\% $(n=6)$ pain in wrist joint, $15.3 \%(n=13)$ had upper back pain, $90.6 \%$ $(n=77)$ had lower back pain, 23.5\% $(n=20)$ had knee joint pain and $2.4 \%(n=2)$ had ankle joint pain. This clearly indicated that respondents had MSDs in multiple locations.

Table 1. Distribution of the respondents based on pattern of MSDs

\begin{tabular}{ccc}
\hline Variable & Number & Percent (\%) \\
Pain Pattern & & 88.1 \\
\hline Temporary & 74 & 3.6 \\
Continuous & 3 & 46.4 \\
On movement & 39 & 138.1 \\
\hline
\end{tabular}

Complaints of temporary pain, continuous pain, pain on movement and with no pain were observed in 74 (88.1\%), 3 (3.6\%), 39 (46.4\%) and 17 (16.7\%) respondents respectively indicating that respondents with MSDs $(n=85)$ had multiple complaints. 
Table 2. Distribution of the respondents based on duration of pain

\begin{tabular}{ccc} 
Variable & Number & Percent (\%) \\
Pain Duration & & 6.9 \\
\hline $1-4$ & 7 & 72.5 \\
$5-8$ & 74 & 3.9 \\
$9-12$ & 4 & 83.3 \\
\hline
\end{tabular}

Among the respondents $(\mathrm{n}=85,83.3 \%)$, duration i.e. stay of pain varied from 1-4 hours in 6.9\%, $(\mathrm{n}=7)$, 5-8 hours in $72.5 \%(\mathrm{n}=74)$ and $9-12$ hours in $3.9 \%(n=4)$ respondents, respectively.

\subsection{Information Related to Treatment Seeking Pattern}

Treatment seeking pattern and their outcomes are presented in Table 3, Table 4 and Table 5, respectively as stated below.

Table 3. Distribution of the respondents based on treatment received

\begin{tabular}{ccc} 
Variable & Number & Percent (\%) \\
Treatment Received & & 49.0 \\
\hline Yes & 50 & 34.3 \\
No & 35 & 83.3 \\
Total & 85 & \\
\hline
\end{tabular}

Among the respondents ( $\mathrm{n}=85,83.3 \%), 50(49.0 \%)$ received treatment and 35(34.3\%) did not receive treatment.

Table 4. Distribution of the respondents based on type of treatment received

\begin{tabular}{ccc}
\hline Variable & Number & Percent (\%) \\
Treatment Types & & 90.0 \\
\hline Medical Doctors & 45 & 2.0 \\
Physiotherapist & 1 & 8.0 \\
Others & 4 & 100 \\
Total & 50 & 0 \\
\hline
\end{tabular}

Out of the 50 respondents taken treatment, 45(90.0\%) went to medical doctors (Physicians), 1(2.0\%) gone to Physiotherapist and 4(8.0\%) of them received other treatments.

Table 5. Distribution of the respondents based on treatment outcome

\begin{tabular}{ccc} 
Variable & Number & Percent (\%) \\
Treatment Outcome & & 34.0 \\
\hline Improved & 17 & 2.0 \\
Worsened & 1 & 64.0 \\
Unchanged & 32 & 100 \\
Total & 50 & 0 \\
\hline
\end{tabular}

Regarding treatment outcome in those 50 respondents, 17(34.0\%) had improvements, 1(2.0\%) were worsened and in 32(64.0\%) condition remained unchanged. 
Statistical Analyses for Associations: Analyses of associations are stated in Table 6 and Table 7, respectively. These analyses indicated that age $(p=0.167)$, BMI $(p=0.155)$, education level $(p=0.329)$ and period of career $(\mathrm{p}=0.293)$ were not significantly associated with MSDs.

Table 6. Associations of Socio-demographic factors with MSDs

\begin{tabular}{|c|c|c|c|c|c|}
\hline & \multicolumn{2}{|c|}{ Musculoskeletal disorders } & \multirow[t]{2}{*}{$\chi^{2}$} & \multirow[t]{2}{*}{ Df } & \multirow[t]{2}{*}{ p-value } \\
\hline & Yes & No & & & \\
\hline \multicolumn{6}{|l|}{ Age } \\
\hline $18-27$ & 45 & 14 & \multirow{5}{*}{6.471} & \multirow{5}{*}{4} & \multirow{5}{*}{0.167} \\
\hline 28-37 & 23 & 2 & & & \\
\hline $38-47$ & 12 & 0 & & & \\
\hline $48-57$ & 3 & 1 & & & \\
\hline $58-67$ & 2 & 0 & & & \\
\hline \multicolumn{6}{|l|}{ BMI } \\
\hline$<18.5$ & 20 & 6 & & & \\
\hline $18.5-24.9$ & 58 & 10 & \multirow{2}{*}{5.239} & \multirow{2}{*}{3} & \multirow{2}{*}{0.155} \\
\hline $25-29.9$ & 0 & 0 & & & \\
\hline 30 and above & 17 & 1 & & & \\
\hline \multicolumn{6}{|l|}{ Education Level } \\
\hline Illiterate & 64 & 16 & \multirow{2}{*}{3.440} & \multirow{2}{*}{3} & \multirow{2}{*}{0.329} \\
\hline Read \& Write & 11 & 0 & & & \\
\hline Below primary level & 8 & 1 & & & \\
\hline Above primary level & 2 & 0 & & & \\
\hline
\end{tabular}

$\mathrm{p} \leq 0.05$ : significant; $\mathrm{p}>0.05$ : Not significant

Table 7. Associations of ergonomic related factors with MSDs

\begin{tabular}{ccccc}
\hline & $\begin{array}{c}\text { Musculoskeletal disorders } \\
\text { Yes }\end{array}$ & No & Df & p-value \\
\hline Period of career (Year) & 4 & 2 & & \\
$1-5$ & 21 & 8 & 5 & 0.293 \\
$6-10$ & 28 & 5 & 6.137 & \\
$11-15$ & 15 & 2 & & \\
$16-20$ & 8 & 0 & & \\
$21-25$ & 4 & 0 & & \\
$26-30$ & & & & \\
\hline
\end{tabular}

$\mathrm{p} \leq$ 0.05: Significant; $\mathrm{p}>0.05$ : Not significant 


\section{Discussion}

Solid waste management encompasses a wide range of activities including collection, transfer, treatment and recycling that require repetitive motions, frequent use of musculoskeletal movement in awkward postures which may lead to development of MSDs. Occupational injuries are any physical injury conditions sustained on a worker in connection with the performance of his or her work [31]. They pose a major public health problem and are a source of substantial human and economic cost in both developed and developing countries [32, 33].

It was revealed that a large majority (85/102; 83.3\%) of MSW disposal male workers had experience of MSD similar to observations reported in another study [34]. Statistically no significant associations between the age groups and MSDs among our MSW disposal male workers were observed $(\mathrm{p}=0.167)$ (Table 4) similar to another reported study $(\mathrm{p}>0.05)$ [18]. However, statistically significant findings $(\mathrm{p}<0.05)$ were reported in another study [35]. In our study, BMI was found not significantly related with MSDs $(p=0.589)$ similar to a previously reported study ( $p>0.5$ ) [18]. However, our results were in contradiction to significant relationship between BMI and MSDs in MSW disposal workers as reported in a previous study ( $\mathrm{p}=0.013$ ) [35].

In the present study, high percentage of musculoskeletal complaints $(83.3 \%, \mathrm{n}=85)$ were detected among MSW collectors, and the lower back $(90.6 \%, \mathrm{n}=77)$ was the most frequently affected body region. High prevalence of MSDs among MSW collectors was reported in studies from Brazil [36]. The independent risk factors for MSDs among MSW collectors were reported to be duration of employment, lifting, pulling, pushing/carrying loads $(>20 / \mathrm{kg}$ ) and walking for long periods of time. The differences in the distribution of musculoskeletal complaints in different types of MSW collectors were statistically not significant, but shown higher in the rag pickers group as reported [34]. These reported observations were contrary to and differ from our present study. The career period of MSW disposal male workers was found not to be significantly associated with MSDs in the present study $(p=0.293)$ (Table 5). However, MSDs were reported to be significantly linked with period of career in another study by Pintakham and Sandul [35].

In many developing countries, MSW is collected manually including household which requires repeated heavy physical activity such as lifting, carrying, pulling, and pushing [8]. The study suggested that MSW workers were mostly engaged in manual handling tasks for waste collection. Though the workers were found to be highly experienced, they had little knowledge about health hazards at their workplace. The nature of duties involved in refuse collection requires the use of relevant protective equipment. Where possible the personal protective equipment should be tried out before general use as suggested by several investigators. Many studies carried out in developed and in some developing countries in this regard were documented in literature and integrated screening of workplace hazards and awareness might help to prevent further development of MSDs among these high-risk groups [19, 34, 35, 37-40].

Despite the fact that MSDs may cause great deal of sufferings among MSW disposal male workers, only small number of them (50/85, i.e., 49\%) received treatment in our study. Of those 50 workers, 45, i.e., 90\% received treatments from doctors and only 1, i.e., $2 \%$ of them received physiotherapy. This pattern of treatment should be changed and perhaps more workers may be encouraged to undertake relevant physiotherapy treatments in addition to medication.

In conclusion, the less educated MSW disposal workers seem to be less aware of the potential hazards and health impacts related to the collection methods. The unfavorable working conditions of MSW collectors could be ameliorated through engineering, medical, and legislative measures as well as a proper workplace health promotion model intervention. As education level was found to be a significant contributing factor for MSDs, an integrated health education consisting of ergonomics and healthy work habits needs to be incorporated in a pre-health screening program. They should be encouraged to undertake more of physiotherapy in addition to medication. In addition, a routine workplace health promotion model needs to be activated for the welfare of these under marginalized population.

Based on the present study findings, recommendations particularly precautions to be followed are noted below: Take regular breaks from working period; Do not do regular weight lifting; Maintain correct posture during work; Use comfortable equipment; Do regular exercise to relax body; Focus on health planning and education and Increase effective approach for primary prevention of MSDs. These may help to prevent and reduce occurrence of MSDs in MSW disposal male workers minimizing impact on the population as whole. Further analytical as well as interventional studies should be conducted including larger number of respondents from wider areas of Dhaka city as well as other parts of Bangladesh to generalize and implement the findings accordingly. This would be helpful for physiotherapists as well as other professionals in this field of research. 


\section{Acknowledgements}

The article was based on the dissertation submitted by Jasim Uddin in February 2018 to the Department of Physiotherapy, State College of Health Sciences (SCHS), Dhanmondi, Dhaka-1209, Bangladesh as partial fulfilment of the requirements for the degree of BSc in Physiotherapy under Faculty of Medicine, University of Dhaka, Dhaka-1000, Bangladesh. The authors gratefully appreciate and acknowledge the authorities of SCHS and Dhaka University for accepting and approving the dissertation in July 2018 towards the BSc degree successfully.

\section{References}

[1] Rushton, L. (2003). Health hazards and waste management. British Medical Bulletin, 68(1): 183-197.

[2] Jayakrishnan, T., Jeeja, M. C., Bhaskar, R. (2013). Occupational health problems of municipal solid waste management workers in India. International Journal of Environmental Health England, 2: 42. DOI: 10.4203/2277-9183.122430.

[3] Kuijer, P., Sluiter, J., Frings-Dresen, M. (2010). Health and safety in waste collection: towards evidence-based worker health surveillance. American Journal of Industrial Medicine, 53: 1040-1064.

[4] Cointreau-Levine, S. (2006). Occupational and environmental health issues of solid waste management-special emphasis on middle and lower-income countries; Washington DC: World Bank Group; 1-48.

[5] Mohammed, S., Patel, A. L. (2014). Possible health danger associated with garbage/refuse collectors. Journal of Environmental Science, Toxicology and Food Technology, 8(9): 22-30.

[6] Sukadarin, E. H., Deros, B. M., Ghani, J. A., Nawi, N. S. M., Ismail, A. R. (2016). Postural assessment in pen-and-paper-based observational methods and their associated health effects: a review. International Journal of Occupational Safety and Ergonomics, 22(3): 389-398. https://doi.org/10.1080/10803548.2016.1156924.

[7] Meksawi, S., Tangtrakulwanich, B., Chongsuvivatwong, V. (2012). Musculoskeletal problems and ergonomic risk assessment in rubber tappers: A Community-based study in Southern Thailand. International Journal of Industrial Ergonomics, 42(1): 129-135.

[8] Mehrdad, R., Majlessi-Nasr, M., Aminian, O., Sharifian, S. A., Malekahmadi, F. (2008). Musculoskeletal disorders among municipal solid waste workers. Acta Medica Iranica, 46: 233-238. https://www.researchgate.net/publication/229001733.

[9] Wouters, I. M., Hilhorst, S. K. M., Kleppe, P., Doekes, G., Douwes, J., Peretz, C., Heederik, D. (2002). Upper Airway Inflammation and Respiratory Symptoms in Domestic Waste Collectors. Occupational Environment Medicine, 59(2): 106-112. https://ome.bmj.com/doi:10.1136/ome.59.2.106.

[10] Dorevitch, S., Marder, D. (2001). Occupational hazards of municipal solid waste workers. Occupational Medicine, 16: 125-133.

[11] Rogers, B. (2001). Municipal healthcare workers: Work-related health hazards. Occupational Medicine, 16: $143-161$.

[12] Leijon, M., Hensing, G., Alexanderson, K. (1998). Gender trends in sick-listing with musculoskeletal symptoms in a Swedish county during a period of rapid increase in sickness absence. Scandinavian Journal of Social Medicine, 26: 204-213.

[13] Karwowski, W., Marras, W. S. (2003). Occupational Ergonomics: Principles of Work Design, Florida: CRC Press, p. 24. eBook ISBN9780429211546.

[14] Occupational Health and Safety Act. (2012). Section 43. Available from: www.e-laws.gov.on.ca/html/statutes/english/ elaws_statutes_97w16_e.htm.

[15] Takala, J. (2011). OH \& S Forum 2011/ Conference on EU Strategies and Tools in Occupational Safety and Health Forum by European Agency for Safety and Health at Work; pp. 77-65. Available from: http://www.osha.europa.eu.

[16] Yasobant, S., Rajkumar, P. (2014). Work-related musculoskeletal disorders among health care professionals: A cross-sectional assessment of risk factors in a tertiary hospital, India. Indian Journal of Occupational Environment Medicine, 18: 75-81.

[17] Porta, D., Milani, S., Lazzarino, A. I., Perucci, C. A., Forastiere, F. (2012). Systematic review of epidemiological studies on health effects associated with management of solid waste. Environmental Health, 8: 60. Available from: https://www.researchgate.net/publication/40766335/doi.org/10.1186/1476-069X-8-60.

[18] Abou-ElWafa, H. S., El-Bestar, S. F., El-Gilany, A.-H., El-Toraby, EEl-S. A. (2012). Musculoskeletal disorders among municipal solid waste collectors in Mansoura, Egypt: A cross-sectional study. British Medical Journal Open, 2(5): e001338. Available from: https://www.researchgate.net/publication/230850535/doi:10.1136/bmlopen-2012-001338.

[19] Commissioner, M. (2012). Administration report of municipal corporation of Greater Mumbai: City-suburbs and extended suburb. Mumbai: Municipal Printing Press; pp. 449-456.

[20] Schibye, B., Sogaard, K., Martinsen, D., Klausen, K. (2001). Mechanical load on the low back and shoulders during pushing and pulling of two-wheeled waste containers compared with lifting and carrying of bags and bins. Clinical Biomechanics 
(Bristol, Avon), 16(7): 549-559. Available from: https://www.clinbiomech.com/doi.org/10.1016/S0268-0033(01)00039-0.

[21] Poulsen, O. M., Breum, N. O., Ebbehøj, N., Hansen, A. M., Ivens, U. I., Lelieveld, D. V., et al. (1995). Collection of domestic waste. Review of occupational health problems and their possible causes. Science of the Total Environment, 170(1-2): 1-19. Available from: https://www.pubmed.ncbi.nlm.nih.gov/doi:10.1016/0048/9697(95)04524-5.

[22] Gizaw, Z., Gebrehiwot, M., Teka, Z., Molla, M. (2014). Assessment of occupational injury and associated factors among municipal solid waste management workers in Gondar town and Bahir Dar City, Northwest Ethiopia. Journal of Medicine and Medical Sciences, 5(9): 181-192. Available from: https://dx.doi.org/10.14303/jmms.2014.103.

[23] Bell, M. L., Samet, J. M., Frumkin, H. (2010). Environmental health: from global to local, Second Edition; Jossey-Bass: USA; pp. 374-587.

[24] Athanasiou, M., Makrynos, G., Dounias, G. (2010). Respiratory health of municipal solid waste workers. Occupational Medicine, 60: 618-623.

[25] London, L., Tangwa, G., Matchaba-Hove, R., Mkhize, N. J., Nyika, A., Westerholm, et al. (2014). Ethics in occupational health: deliberations of an international workgroup addressing challenges in an African context. Biomedical Central Medical Ethics, 15: 48. Available from: https://doi.org/10.1186/1472-6939-15-48.

[26] Thirarattanasunthon, P., Siriwong, W., Robson, M., Borjon, M. (2012). Health risk reduction behaviors model for scavengers exposed to solid waste in municipal dump sites in Nakhon Ratchasima Province, Thailand. Risk Management of Health Policy, 5: 97-104. Available from: https://doi:10.2147/RMHP.S30707. Corpus ID:6097568.

[27] Bogale, D., Kumie, A., Tefera, W. (2014). Assessment of occupational injuries among Addis Ababa city municipal solid waste collectors: a cross-sectional study. BMC Public Health, 14: 169. Available from: https://doi.org/10.1186/1471-2458-14-169.

[28] Kuijer, P. P. F. M., Frings-Dresen, M. H. W. (2004). World at work: Refuse collectors. Occupational and Environmental Medicine, 61(3): 282-286. Available from: https:/www.researchgate.net/pulication/7254536/Doi:10.1136/oem.2002.001172.

[29] Heldal, K. K., Straumfors, A., Thorn, J., Djupesland, P., Wouters, I., Eduare, W., Halstensen, T. S. (2003). Upper Airway Inflammation in Waste Handlers Exposed to Bioaerosols. Occupational and Environmental Medicine, 60(6): 444-450. https://www.researchgate.net/publication/10739877/Doi:10.1136/oem.60.6.444.

[30] WMA. (2013). World Medical Association Declaration of Helsinki: Ethical Principles of Medical Research Involving Human Subjects. Journal of American Medical Association, 310 (20): 2191-2194. Available from: https://www.jamanetwork.com/ journals/jama/fullarticle/1760318.

[31] Aderaw, Z., Engdaw, D., Tadesse, T. (2011). Determinants of occupational injury: a case control study among textile factory workers in Amhara Regional State, Ethiopia. Journal of Tropical Medicine (Article ID 657275). DOI: https://doi.org/10.1155/2011/657275. Available from: https://www.hindawi.com/journals/jtm/2011/657275.

[32] Yiha, O., Kumie, A. (2010). Assessment of occupational injuries in Tendaho Agricultural Development S.C, Afar Regional State. Ethiopian Journal of Health Development, 24(3): 167-174.

[33] Olorunnishola, O. A., Taylor, A. K., Byrd, L. (2010). Occupational injuries and illnesses in the solid waste industry: a call for action; New Solutions. A Journal of Environmental and Occupational Health Policy, 20(2): 211-223. https://www.doi:10.2190/NS.20.2.f.

[34] Endreddy, M. R., Sandul, Y. (2015). Musculoskeletal disorders among municipal solid waste workers in India: A cross-sectional risk assessment. Journal of Family Medicine and Primary Care, 4(4): 519-524.

[35] Pintakham, K., Siriwrong, W. (2016). Prevalence and risk factors associated with musculoskeletal discomfort among street sweepers in Chiang Rai Province, Thailand. Journal of Health Research, 30(3): 207-213.

[36] Robazzi, M. L. C. C., Moriya, T. M., Favero, M. (1997). Garbage collectors: occupational accidents and coefficients of frequency and severity per accident. Annals of Agricultural and Environmental Medicine, 4(1): 91-96.

[37] Ekpenyong, C. E., Inyang, C. U. (2014). Associations between worker characteristics, workplace factors and work-related musculoskeletal disorders: A cross-sectional study of male construction workers in Nigeria. International Journal of Occupational Safety and Ergonomics, 20(3): 447-462. Available from: https://dx.doi.org/10.1080/10803548.2014.11077057.

[38] Zakaria, J., Sukadarin, E. H., Omar, F. A. C., Salleh, N. F. M. (2017). Musculoskeletal disorder among municipal solid waste collectors. Asia Pacific Environmental and Occupational Health Journal, 3(1): 28-32.

[39] Decharat, S. (2017). Prevalence of adverse Health Effects among municipal solid waste workers, Southern Thailand. International Journal of occupational Hygiene, 9(4): 186-191.

[40] Eskezia, D., Alemu, A. Z., Ahmed, K. Y., Tadese, F. (2016). Prevalence and associated factors of occupational injuries among municipal solid waste collectors in four zones of Amhara region, Northwest Ethiopia. BioMedical Central Public Health, 16: 862. Available from: http://www.researchgate.net/publication/306425188/doi.org/10.1186/s12889-016-3483-1. 